\title{
Research Article \\ Skin Friction Reduction Characteristics of Nonsmooth Surfaces Inspired by the Shapes of Barchan Dunes
}

\author{
Xiao-wen Song, Ming-xiao Zhang, and Peng-zhe Lin \\ State Key Laboratory of Fluid Power and Mechatronic Systems, Zhejiang University, Hangzhou 310027, China \\ Correspondence should be addressed to Xiao-wen Song; songxw@zju.edu.cn
}

Received 9 March 2017; Revised 18 April 2017; Accepted 2 May 2017; Published 24 May 2017

Academic Editor: Sandro Longo

Copyright (C) 2017 Xiao-wen Song et al. This is an open access article distributed under the Creative Commons Attribution License, which permits unrestricted use, distribution, and reproduction in any medium, provided the original work is properly cited.

\begin{abstract}
A new type of nonsmooth surface inspired by the shape of barchan dunes has been proposed and is intended to reduce skin friction, a major cause of overall drag. Simulations were carried out to obtain skin friction reduction characteristics for the nonsmooth surface using the commercial computational fluid dynamics software Fluent. A realizable $k-\varepsilon$ model was employed to assess the influence of the nonsmooth structure on turbulent flow and velocity fields. The numerical simulation results showed that the new nonsmooth surface possesses the desired skin friction reduction effect and that the maximum skin friction reduction percentage reached $33.63 \%$ at a fluid speed of $30 \mathrm{~m} / \mathrm{s}$. Various aspects of the skin friction reduction mechanism were discussed, including the distribution of velocity vectors and shear stress contours and the variations in boundary layer thickness. The accuracy of the flow field for the nonsmooth unit was further verified by particle image velocimetry test results. The new bionic nonsmooth surface, which exceeds the limitations of existing nonsmooth bionic structures, can effectively reduce skin friction and should provide insights into engineering applications in the future.
\end{abstract}

\section{Introduction}

With the rapid growth in energy consumption, the global energy crisis has been become increasingly serious. There is obviously a significant need to lower the overall drag in next generation transportation systems to accommodate environmental constraints [1]. It is therefore important to reduce skin friction, a major cause of overall drag, for the purposes of energy conservation.

Skin friction reduction is not a new topic. A vast number of effective methods have been proposed in previous studies, which can be roughly divided into active drag reduction methods and passive drag reduction methods. Active drag reduction methods, such as the supercavity method [2] and periodic perturbation method [3], achieve drag reduction via external interference, which leads to changes in the flow field around an object. However, extra energy is needed to implement these methods for drag reduction. In contrast, passive drag reduction methods, such as surface coating methods [4, 5], flexible wall methods [6], and bionic nonsmooth surface methods [7], achieve drag reduction by changing the shape of an object or its surface structure, without the need for extra energy inputs. Elbing et al. [8] conducted a set of experiments to investigate the phenomenon of skin friction reduction, which includes bubble drag reduction (BDR) and air-layer drag reduction (ALDR) in a turbulent boundary layer at large scales and high Reynolds numbers. From these experiments they observed that BDR and ALDR have significant drag reduction effects; however, the effects of BDR are limited to the first few meters downstream of the injection location, and ALDR is sensitive to inflow conditions. Sanders et al. [9] also observed that, at lower flow speeds and higher gas injection rates, a layer of gas would form on the underside of a flat plate and persist along its entire length. Such air layers lead to skin friction reductions greater than $80 \%$. However, significant BDR levels could only be achieved near the injection location. Mamori and Fukagata [10] performed a direct numerical simulation of a fully developed channel flow controlled by a traveling wave-like or stationary wall-normal body force. The friction drag is reduced when the wave travels at slower wave speeds than the bulk-mean velocity, and a maximum drag reduction rate of about $40 \%$ is achieved in the case of a stationary control input. 
Through evolution, different organisms develop unique surfaces for better environmental adaptation. These nonsmooth surfaces, such as the nonsmooth structures on the pelage of bats [11] and the riblet structures on shark skin [12], have become a type of widely accepted functional surface.

Bionic nonsmooth drag reduction technology provides a new method for energy saving. Many biologically inspired engineering innovations have been achieved in recent years. Dean and Bhushan [13] applied the riblet structure to a rectangular pipe and found a maximum drag reduction rate of $10 \%$. Dou et al. [14] studied the drag reduction characteristics of fish scale surfaces and found that the microscale nonsmooth structures on fish scale surfaces have a significant effect on skin friction reduction. Bixler and Bhushan [15] applied the groove structure to a closed pipe. From the test results, it was found that a closed pipe with nonsmooth structures can reduce flow resistance significantly and that the drag reduction effect is closely related to the size of the groove structure and layout position. EI-Samni et al. [16, 17] studied the relationship between the geometric parameters of a riblet structure and the drag reduction rate. This was accomplished by stabilizing the mass flow rate. The maximum drag reduction rate reached $11 \%$.

Bionic nonsmooth structures have been successfully applied to drag reduction not only in the laboratory but also in industrial applications. There are many methods available to fabricate large-scale nonsmooth surfaces, such as nonsmooth film coating, bioreplication methods, precision cutting methods, and 3D printing methods. Szodruch [18] reported an estimated $2 \%$ reduction in the total drag force on flight tests of the Airbus 320, with riblet structures covering over $70 \%$ of its surface. The nonsmooth structures have also been used on golf balls to make them fly farther with a more controllable route. Huang et al. [19] studied the drag reduction characteristics of underwater vehicles with transverse surfaces and showed that the maximum drag reduction effect can reach $11.7 \%$. Luo and Zhang [20] used a coating with nonsmooth structures on a natural gas pipeline surface, and a reduction efficiency in drag of $8 \%$ was validated in field testing.

Research on bionic nonsmooth surfaces has a long history and has been widely used in engineering applications. However, a unified recognition of the drag reduction mechanism has not been proposed, because of unsolved issues or controversies in turbulence theory. Secondary vortex theory [21] and protrusion height theory [22] are the two widely accepted theories at present. Secondary vortex theory proposes that the existence of the nonsmooth structure suppresses the pulsation of the horizontal vortex in the turbulent boundary layer, reducing the loss of turbulent energy and weakening the friction effects between the fluid and object surfaces. Protrusion height theory contends that the nonsmooth structure can increase the thickness of the turbulent boundary layer, slow the velocity gradient, and weaken the wall shear stress. However, these theories are limited to groove surfaces and have yet to be extended in a convincing manner to other types of nonsmooth structures.

With the rapid development of computational mathematics, computational fluid dynamics (CFD) has been widely applied in engineering practice because of advantages of short calculation period and low cost. Yao et al. [23] conducted an optimal design for the aerodynamic nose shapes of highspeed trains using modified multiobjective particle swarm optimization. The numerical simulation results showed the aerodynamic drag for the whole train $(\mathrm{Cd})$ and aerodynamic lift for the trailer car $(\mathrm{Cl})$ of the optimal shape are reduced by $1.6 \%$ and $29.74 \%$, respectively. Kim et al. [24] used the CFD software OpenFOAM to characterize swirling secondary flow downstream of a pipe bend. The study found that the swirl intensity of the secondary flow is a strong function of the bend curvature radius and a weak function of the Reynolds number. Dong and Cao [25] studied the effects of the residual riblets of an impeller hub surface on the aerodynamic performance of a compressor. The simulation results showed that the reasonable size and structure of residual riblets can reduce the average shear stress on the hub surface and the viscous drag of the boundary layer on the hub surface, increasing the overall efficiency of the compressor. Sun et al. [26] studied the unsteady aerodynamic performance of three-carriage CRH3 high-speed trains passing by each other both in a tunnel and in open air, using CFD numerical simulation methods. The results provide guidance for the safe running of trains passing by each other in real-world scenarios.

The preceding studies show that the existing nonsmooth unit type is typically onefold and is limited to groove and riblet structures. The current study proposed a new nonsmooth unit inspired by the shape of barchan dunes. The primary aim of the current study was to investigate the skin friction reduction performance of a new bionic nonsmooth unit. The study focused on the effects of changes in various structural parameters on skin friction reduction, using an orthogonal experimental method. Emphasis was placed on exploring skin friction reduction mechanisms. To verify the accuracy of a flow field in a nonsmooth unit predicted by numerical simulation, a particle image velocimetry (PIV) test was conducted in a low-speed reflux wind tunnel. A theoretical basis was established for the design and optimization of nonsmooth surfaces.

\section{Numerical Simulation Preprocessing}

2.1. The Establishment of Physical Model. The barchan-duneinspired bionic nonsmooth units (Figure 1) are based on barchan dunes, the simplest and best known type of dunes, which can frequently be found in deserts, beaches, and riverbeds. Barchan dunes are shaped by the wind, which blows steadily in the same direction throughout the years and have a strong ability to maintain their geometric shapes.

A geometry quantitative model describing barchan dune shape proposed by Sauermann et al. [27] was adopted in this study. The model agrees quite well with the results of actual measurements in southern Morocco. A cross-section of the barchan dune was constructed as a simple geometric shape 
TABLE 1: Turbulent boundary layer thickness of nonsmooth surfaces.

\begin{tabular}{lcccc}
\hline$L(\mathrm{~mm})$ & $\begin{array}{c}\text { Minimum boundary } \\
\text { layer thickness } \\
(\mathrm{mm})\end{array}$ & $\begin{array}{c}\text { Maximum boundary } \\
\text { layer thickness } \\
(\mathrm{mm})\end{array}$ & $\begin{array}{c}\text { Minimum wall } \\
\text { region thickness } \\
(\mathrm{mm})\end{array}$ & $\begin{array}{c}\text { Maximum wall } \\
\text { region thickness } \\
(\mathrm{mm})\end{array}$ \\
\hline 300 & 7.74 & 9.64 & 1.55 & 1.92 \\
1000 & 20.27 & 25.25 & 4.05 & 5.05 \\
\hline
\end{tabular}

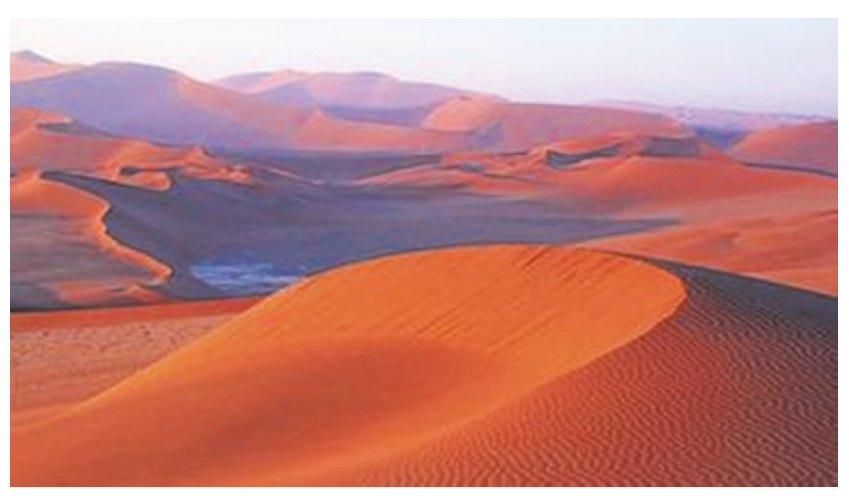

FIGURE 1: Barchan dune topography.

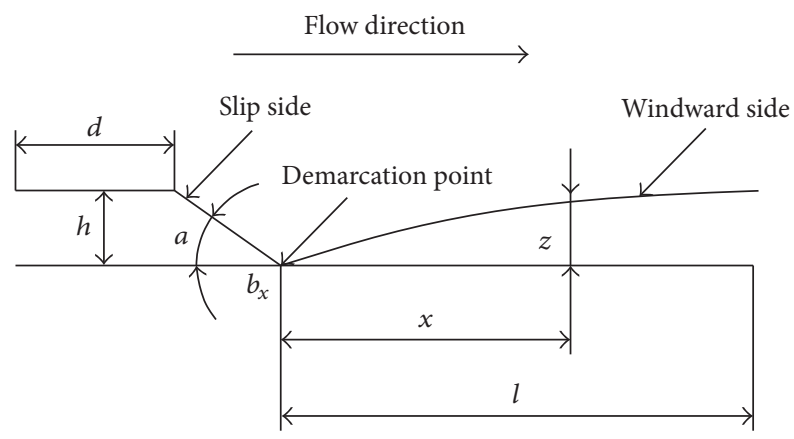

FIGURE 2: Cross-section parameters of a nonsmooth unit.

consisting of a parabola and a straight line (Figure 2). The equation was defined as presented as follows:

$$
\begin{aligned}
& z=h\left(1-\frac{1}{l^{2}} x^{2}\right) \quad \text { with } z \geq 0, x \leq b_{x}, \\
& z=\tan (-\alpha)\left(x-b_{x}\right)+z\left(b_{x}\right) \quad \text { with } z \geq 0, x>b_{x},
\end{aligned}
$$

where $h$ is the depth of barchan dunes, $\alpha$ is the angle of repose, $l$ is the half length of the parabola defined by $l=$ $5.4 h+10.7, b_{x}$ is the demarcation point that separates the parabola from the straight line, which was defined as $b_{x}=$ $-2.4 h+7.9, x$ is the independent variable that represents the horizontal distance from the separation point $\left(b_{x}\right)$, and $z$ is the dependent variable that represents the vertical height of the barchan dune at point $x$.

According to (1), depth $(h)$ and angle of repose $(\alpha)$ are the two main parameters of the barchan dune model. To investigate the drag reduction effect caused by the spacing between each bionic nonsmooth structure, parameter spacing $(d)$ was introduced (Figure 2).

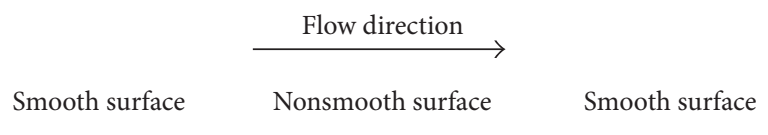

Figure 3: Cross-section of the nonsmooth surface.

The cross-section of the nonsmooth surface is shown in Figure 3. There are two smooth surfaces, in the front and back of the nonsmooth surface. The front surface was used to create a transition phase before the fluid flows through the nonsmooth area, to ensure a steady flow field. The back surface was used to compare the results with the front surface, to allow the changes in the nearby wall flow field after flowing over the nonsmooth unit to be studied.

The angle of repose $(\alpha)$ is an intrinsic property of the sand and is therefore independent of Aeolian processes. Based on results measured in Peru, Namibia, and Morocco, the angle typically has a value between $31^{\circ}$ and $35^{\circ}$.

Minimizing the burst in the turbulent boundary layer that occurs in the wall region is a commonly used method for reducing drag. Therefore, the depth of the nonsmooth unit (h) should be larger than the thickness of the wall region, but smaller than the thickness of the turbulent boundary layer. The wall region is usually less than $20 \%$ of the thickness of the turbulent boundary layer. The calculation equations of the turbulent boundary layer thickness of a plate are shown as follows:

$$
\begin{aligned}
\delta_{L} & =0.37 \frac{L}{\operatorname{Re}_{L}^{1 / 5}}, \\
\operatorname{Re}_{L} & =\frac{U_{\infty} L}{v},
\end{aligned}
$$

where $L$ is the distance from the calculation point to the front end of plate, $\delta_{L}$ is the turbulent boundary layer thickness, $\operatorname{Re}_{L}$ is Reynolds number, $U_{\infty}$ is the fluid flowing velocity, and $v$ is the coefficient of kinematic viscosity.

Considering applications to automobiles and other ground vehicles, the fluid flowing velocity $\left(U_{\infty}\right)$ was broadly defined to range from $10 \mathrm{~m} / \mathrm{s}$ to $30 \mathrm{~m} / \mathrm{s}$. The coefficient of kinematic viscosity $(v)$ of air is $1.48 \times 10^{-5} \mathrm{~m}^{2} / \mathrm{s}$. The corresponding Re ranges from $8.78 \times 10^{5}$ to $2.17 \times 10^{6}$, so the flow field is in a turbulent state in this paper.

The turbulent boundary layer thickness and wall region thickness at the beginning of the nonsmooth structure $(L=$ $300 \mathrm{~mm})$ and the back end of the nonsmooth structure $(L=$ $1000 \mathrm{~mm}$ ) were shown in Table 1 . According to Table 1, the 


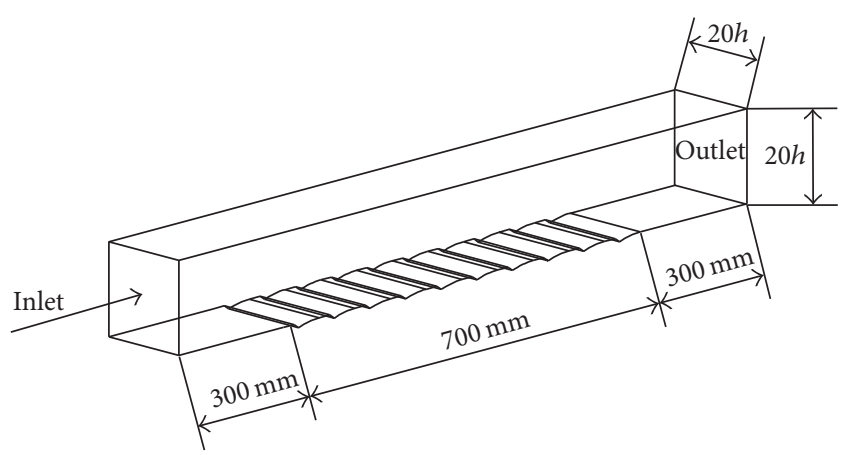

FIGURE 4: Simulation model of a nonsmooth surface.

design scope for the depth of the nonsmooth unit $(h)$ was as follows:

$$
5.05 \leq h \leq 7.74 \text {. }
$$

To investigate the skin friction reduction effect caused by the depth $(h)$, three depth levels were defined in orthogonal tests which were defined as $4 \mathrm{~mm}$ (less than the design scope), $9 \mathrm{~mm}$ (larger than the design scope), and $7 \mathrm{~mm}$ (matching the design scope). Three-dimensional models of nonsmooth surfaces were constructed using the modeling software Siemens Unigraphics NX 8.5.

2.2. Calculation Domain Selection. A square tube model was adapted as the computational domain. To normalize the flow field conditions, the smooth surface and nonsmooth surface were calculated in the same computing domain. The nonsmooth surface was set on the bottom of the square tube model, and the smooth surface was set on the top. To avoid the mutual influence between the upper and lower wall of the square tube model, the height of the numerical wind tunnel was defined to be 20 times of the depth of the nonsmooth unit (h) (Figure 4). The square tube model was constructed using the software Siemens Unigraphics NX 8.5.

2.3. The Calculation Model. The fluid field was calculated and analyzed by an incompressible model, in which thermodynamic effects were not considered. As a result, the primary transport variables were governed by the conservation equations of mass and momentum.

Mass equation is as follows:

$$
\frac{\partial \rho}{\partial t}+\frac{\partial(\rho u)}{\partial x}+\frac{\partial(\rho v)}{\partial y}+\frac{\partial(\rho w)}{\partial z}=0
$$

Momentum equation is as follows:

$$
\begin{aligned}
\frac{\partial(\rho u)}{\partial t}+\operatorname{div}(\rho u \mathbf{u})= & -\frac{\partial p}{\partial x}+\frac{\partial \tau_{x x}}{\partial x}+\frac{\partial \tau_{y x}}{\partial y}+\frac{\partial \tau_{z x}}{\partial z} \\
& +F_{x}, \\
\frac{\partial(\rho v)}{\partial t}+\operatorname{div}(\rho v \mathbf{u})= & -\frac{\partial p}{\partial y}+\frac{\partial \tau_{x y}}{\partial x}+\frac{\partial \tau_{y y}}{\partial y}+\frac{\partial \tau_{z y}}{\partial z} \\
& +F_{y},
\end{aligned}
$$

$$
\begin{aligned}
\frac{\partial(\rho w)}{\partial t}+\operatorname{div}(\rho w \mathbf{u})= & -\frac{\partial p}{\partial z}+\frac{\partial \tau_{x z}}{\partial x}+\frac{\partial \tau_{y z}}{\partial y}+\frac{\partial \tau_{z z}}{\partial z} \\
& +F_{z} .
\end{aligned}
$$

The fluctuating values lead to the emergence of Reynolds stress terms in the Reynolds-averaged equations. A turbulence model must be introduced in order to close the equations and solve each physical quantity in the flow field. Faheem et al. [28] analyzed the air flow developing in a smooth horizontal pipe using five turbulence models. The results showed that the realizable $k-\varepsilon$ model was suitable for describing a complete boundary layer. Li et al. [29] conducted a pressure drop analysis of a dimpled enhanced tube using experimental and numerical simulation techniques; a realizable $k-\varepsilon$ model was employed to assess the influence of the dimples on turbulent flow and the velocity field. A comparison between the experimental and numerical simulation results showed sufficient agreement. To test the performance of the realizable $k-\varepsilon$ model for wall bounded flows, Shih et al. [30] calculated the turbulent channel flow and boundary layer flow with and without pressure gradients. The results showed that the realizable $k-\varepsilon$ model produces better predictions of boundary layer thickness. Therefore, a realizable $k-\varepsilon$ model was used to investigate the influence of this new bionic structure on skin friction reduction performance.

The equations for turbulent kinetic energy $k$ and rate of energy dissipation $\varepsilon$ are as follows:

$$
\begin{aligned}
\frac{\partial(\rho k)}{\partial t}+\frac{\partial\left(\rho k u_{i}\right)}{\partial x_{i}}= & \frac{\partial}{\partial x_{j}}\left[\left(\mu+\frac{\mu_{t}}{\sigma_{k}}\right) \frac{\partial k}{\partial x_{j}}\right]+G_{k} \\
& -\rho \varepsilon, \\
\frac{\partial(\rho \varepsilon)}{\partial t}+\frac{\partial\left(\rho k u_{i}\right)}{\partial x_{i}}= & \frac{\partial}{\partial x_{j}}\left[\left(\mu+\frac{\mu_{t}}{\sigma_{\varepsilon}}\right) \frac{\partial \varepsilon}{\partial x_{j}}\right]+\rho C_{1} E \varepsilon \\
& -\rho C_{2} \frac{\varepsilon^{2}}{k+\sqrt{v \varepsilon}} .
\end{aligned}
$$

The standard wall function, which is suitable for use in a high-Reynolds-number turbulence model, was used for the near-wall treatment. A detailed description of the wall functions is shown as follows. The production of kinetic energy $G_{k}$ and dissipation rate $\varepsilon$ at the wall-adjacent cells, which are the source terms in the $k$ equation, are computed on the basis of the local equilibrium hypothesis. Under this assumption, the production of $k$ and its dissipation rate are assumed to be equal in the wall-adjacent control volume. Thus, the production of $k$ is based on the logarithmic law and is computed by

$$
G_{k} \approx \tau_{w} \frac{\delta u}{\delta y}=\tau_{w} \frac{\tau_{w}}{\kappa \rho C_{\mu}^{1 / 4} k_{p}^{1 / 2} y_{p}},
$$

while $\varepsilon$ is computed by

$$
\varepsilon_{p}=\frac{C_{\mu}^{3 / 4} k_{p}^{3 / 2}}{k y_{p}} .
$$




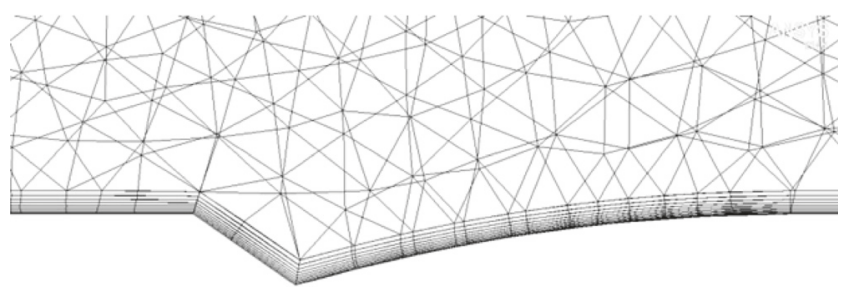

FIGURE 5: Refinement inflation layer.

The expressions for the variables in the above equations follow those in published studies and are therefore not listed here $[30,31]$.

2.4. The Division of the Grid. The grid model for the square tube was generated as unstructured grids by ICEM 14.5. To meet the calculation needs of the near-wall area, inflation layers (controlled by the initial height and number of layers) were set on both the top and bottom of the square tube (Figure 5). The number of layers was set as 10, and the calculation equations for initial height were set as follows:

$$
\begin{aligned}
C_{f} & =0.058 \mathrm{Re}^{-0.2}, \\
\tau_{w} & =\frac{1}{2} c_{f} \rho U_{\infty}^{2}, \\
U_{\tau} & =\sqrt{\frac{\tau_{w}}{\rho}}, \\
y & =\frac{y^{+} \mu}{U_{\tau} \rho},
\end{aligned}
$$

where $C_{f}$ is the skin friction coefficient, Re is the Reynolds number, $\tau_{w}$ is the wall shear stress, $\rho$ is the fluid density (which has a value of 1.225), $U_{\infty}$ is the fluid flowing velocity, $U_{\tau}$ is the velocity estimated by the wall shear stress, $y$ is the initial height, $y^{+}$is a nondimensional parameter that indicates the distance to the wall (which has a value of 50), and $\mu$ is the dynamic viscosity.

To verify the independence of the computational grid, the inlet velocity was set as $30 \mathrm{~m} / \mathrm{s}\left(\operatorname{Re}=2.17 \times 10^{6}\right)$, and the skin frictions of smooth and nonsmooth surfaces were calculated in Fluent 14.5 under five grids with different densities. The calculation results showed that when the grid quantity reaches 2747751, the calculated values of the two parameters remain approximately the same (Table 2 ). Therefore, the grid was adopted as the subsequent computing grid.

2.5. The Boundary Conditions. Fluent 14.5 was used for numerical simulation. The inlet velocity was variably set at $10,15,20,25$, and $30 \mathrm{~m} / \mathrm{s}$. The outlet boundary condition was defined as the outlet pressure, and other wall boundary conditions were defined as stationary walls.

(1) Inlet boundary condition: a uniform incoming fluid velocity is set at the entrance of the computation region. The velocity was set as follows:

$$
\begin{aligned}
& u=10,15,20,25,30, \\
& v=w=0 .
\end{aligned}
$$

TABLE 2: Validation of the grid independence.

\begin{tabular}{lcc}
\hline Grid quantity & $\begin{array}{c}\text { Skin friction of } \\
\text { nonsmooth } \\
\text { surfaces }(N)\end{array}$ & $\begin{array}{c}\text { Skin friction of } \\
\text { smooth surfaces } \\
(N)\end{array}$ \\
\hline 475960 & 0.2985 & 0.4685 \\
1316163 & 0.3081 & 0.4851 \\
1845908 & 0.3106 & 0.4859 \\
2747751 & 0.3291 & 0.4959 \\
3273305 & 0.3281 & 0.4941 \\
\hline
\end{tabular}

(2) Outlet boundary condition: the flow is assumed to be fully developed, and the pressure and velocity are set as follows:

$$
\begin{aligned}
p & =0, \\
\frac{\delta u}{\delta x} & =\frac{\delta v}{\delta x}=\frac{\delta w}{\delta x}=0 .
\end{aligned}
$$

(3) Wall boundary condition: a no-slip boundary condition is adopted, and the velocity was set as follows:

$$
u=v=w=0 .
$$

2.6. Other Preprocessing Settings. A pressure-based solver calculation mode (which is commonly used with low-speed incompressible flows) was selected. A second-order upwind format, which has higher precision and can reduce the false diffusion observed in the discrete format, was used to describe the dissociation of the turbulent kinetic energy and turbulence dissipation rate. A standard discrete format was used for the pressure term. The SIMPLEC algorithm was chosen for its advantages of high stability and fast convergence, and every calculation was set to iterate 500 times before achieving convergence. The default convergence accuracy in Fluent was adopted in this study. The calculation was considered to be convergent when the residual values of all variables were lower than $10^{-3}$, except for the residual value for energy. The convergence criterion for the residual energy value was lower than $10^{-6}$. The import and export flows maintain stability when residual values are reduced below $10^{-3}$ by monitoring import and export flows in Fluent.

\section{Results and Discussion}

3.1. Numerical Simulation. The orthogonal experiment method is a type of scientific method that uses partial tests instead of comprehensive tests to discover an optimal solution, using a standardized orthogonal table. The method selects representative test points for carrying out the test and analyzes the representative results, in order to understand the comprehensive test characteristics. Ultimately, this reduces the number of tests and shortens the test cycle. The orthogonal experiment method is one of the most commonly used optimization design and analysis methods. The method has been widely used in the optimization design of nonsmooth surface $[32,33]$. 


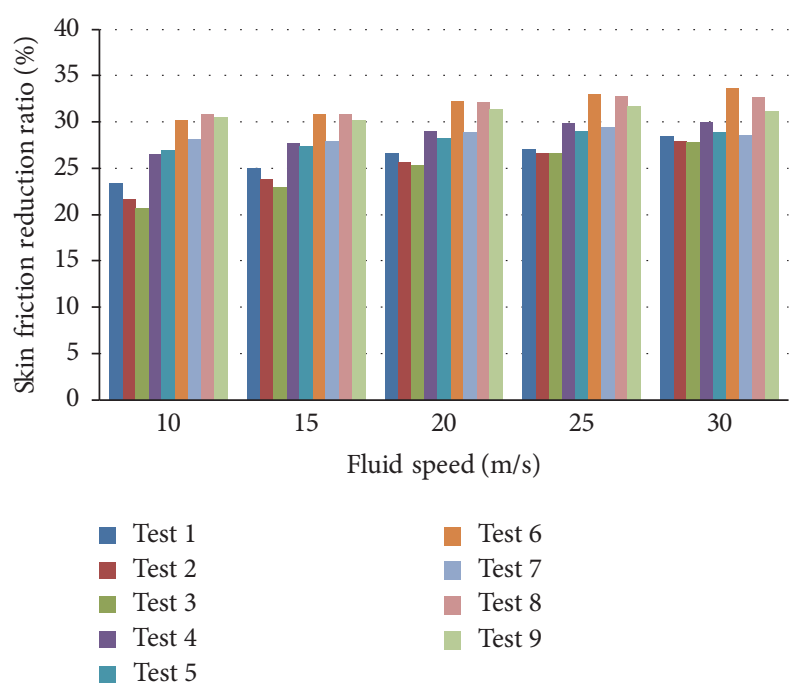

FIGURE 6: Orthogonal test results.

TABLE 3: Level factors.

\begin{tabular}{lccc}
\hline Level & Depth $(\mathrm{mm})$ & Angle of repose $\left(^{\circ}\right)$ & Spacing $(\mathrm{mm})$ \\
\hline 1 & 4 & 31 & 25 \\
2 & 7 & 33 & 30 \\
3 & 10 & 35 & 35 \\
\hline
\end{tabular}

The skin friction of nonsmooth surfaces was studied here for inlet velocities ranging from 10 to $30 \mathrm{~m} / \mathrm{s}$. An orthogonal test was used to study the skin friction reduction for the nonsmooth surfaces, which was evaluated by the skin friction reduction ratio $\left(R_{D}\right)$. The skin friction reduction ratio was calculated using the following equation:

$$
R_{D}=\frac{F_{\text {smooth }}-F_{\text {nonsmooth }}}{F_{\text {smooth }}} \times 100 \%
$$

where $F_{\text {smooth }}$ is the skin friction of a model with smooth surfaces and $F_{\text {nonsmooth }}$ is the skin friction of a model with nonsmooth surfaces.

To investigate a skin friction reduction ratio influenced by depth $(h)$, angle of repose $(\alpha)$, and spacing $(d), L_{9}\left(3^{4}\right)$ orthogonal table was chosen. The sets for level factors are presented in Table 3 , and the test plan was set as presented in Table 4.

A series of tests were conducted on the test plan using Fluent 14.5. The test results are shown in Figure 6. The nonsmooth surfaces showed better skin friction reduction performance relative to smooth surfaces. The skin friction reduction percentage reached values higher than $20 \%$, and the maximum skin friction reduction percentage reached $33.63 \%$ in test 6, when Re reached $2.17 \times 10^{6}$ (Figure 6).

Range and variance analyses were conducted to study key influencing factors and the optimal combination of the three parameters. The numerical simulation results for bionic nonsmooth surfaces were applied to the range analysis table and variance analysis table for analysis (such as that shown for a fluid speed of $30 \mathrm{~m} / \mathrm{s}$ ) (see Tables 5 and 6).
$K_{n}$ is the sum of the results $\left(R_{D}\right)$ at level $n$ for each parameter. $k_{n}$ is the average value of $K_{n}$ that can be used to determine the optimal level for each factor. The combination that gives the optimal level for each factor is regarded as the optimal combination. $R$ is the difference between the maximum and minimum $k_{n}$ and can be calculated as $R_{n}=$ $\max \left(k_{n}\right)-\min \left(k_{n}\right)$.

According to the range analysis, it is obvious that the primary and secondary sequences influencing the skin friction drag reduction ratio were factor $C$ (spacing), factor $A$ (depth), and factor $B$ (the angle of repose). The optimal combination $A_{2} B_{3} C_{1}$ was a $7 \mathrm{~mm}$ depth, a $35^{\circ}$ angle of repose, and a spacing of $25 \mathrm{~mm}$. This combination of variables produced the most significant skin friction reduction. The optimal level of factor $A$ (depth) was $7 \mathrm{~mm}$, which was in the design scope from (3). The result verifies that the depth of the nonsmooth unit should be larger than the thickness of the wall region, but smaller than the thickness of the turbulent boundary layer.

When $\alpha \leq 0.1$, the factor is usually defined as the significant factor for practical engineering. From the variance analysis, it is evident that depth $(h)$ and spacing $(d)$ had significant effects on skin friction reduction, with spacing $(d)$ being most significant.

3.2. Skin Friction Reduction Mechanism. The magnitude of skin friction is the integrated performance of the interaction between the fluid and object surfaces. Changes in the internal structure and main physical quantities of the turbulent boundary layer contribute to reductions in skin friction. The nearby wall velocity vector, changes in the boundary layer thickness, and the wall shear stress of the nonsmooth surface were all discussed here. Because the maximum reduction in skin friction was obtained in test 6 , when the value of Re reached $2.17 \times 10^{6}$, test 6 was used for analysis.

3.2.1. Analysis of Nearby Wall Velocity Vector. A velocity vector graph of the flow field along the middle cross-section was extracted (Figure 7). Figure 8 shows an enlargement of region 1 . The velocity vector graph can be obtained from Figures 7 and 8, in which the surrounding low-speed fluid is absorbed by the nonsmooth structure. A velocity component perpendicular to the nonsmooth surface is produced when fluid flows through the openings of the nonsmooth structures. The consistent flow located in the turbulent boundary layer can be considered as a coherent structure. As the trigger source, the nonsmooth structure stimulates the generation of coherent structures and creates regular disturbances in the turbulent fluid in the turbulent boundary layer. The generation and development of coherent structures can effectively weaken the concentration and acceleration of a low-speed fluid, reduce the turbulent burst strength, improve the motion stability of the boundary layer fluid, and weaken the momentum exchange within the boundary layer, thus resulting in turbulent skin friction reduction. Experiments on the number and undulation of low-speed streak structures conducted by Robinson [34] also confirm that a nonsmooth surface can reduce the turbulent burst strength. Therefore, a nonsmooth structure can reduce skin friction by controlling the coherent structures in the turbulent boundary layer. 

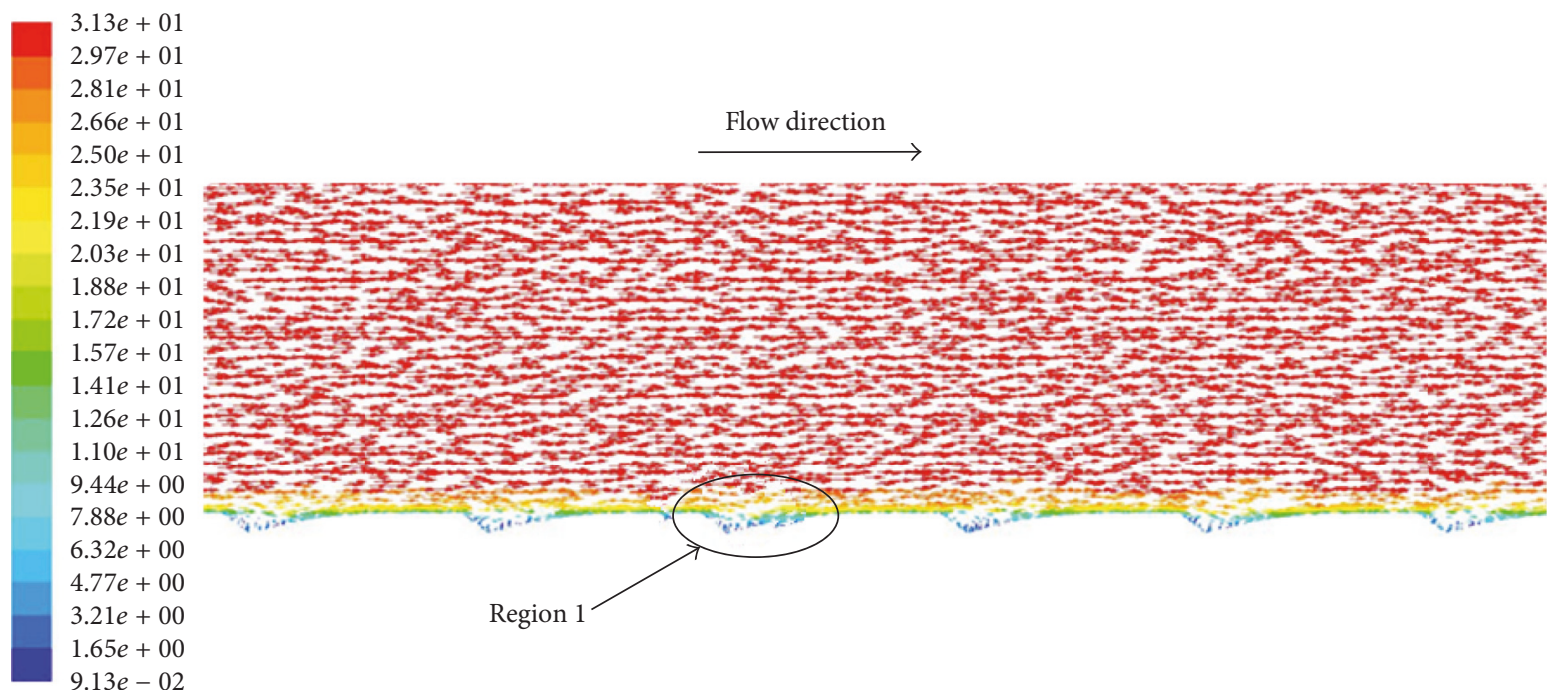

FIGURE 7: Velocity vectors for the nonsmooth surface at the middle cross-section.
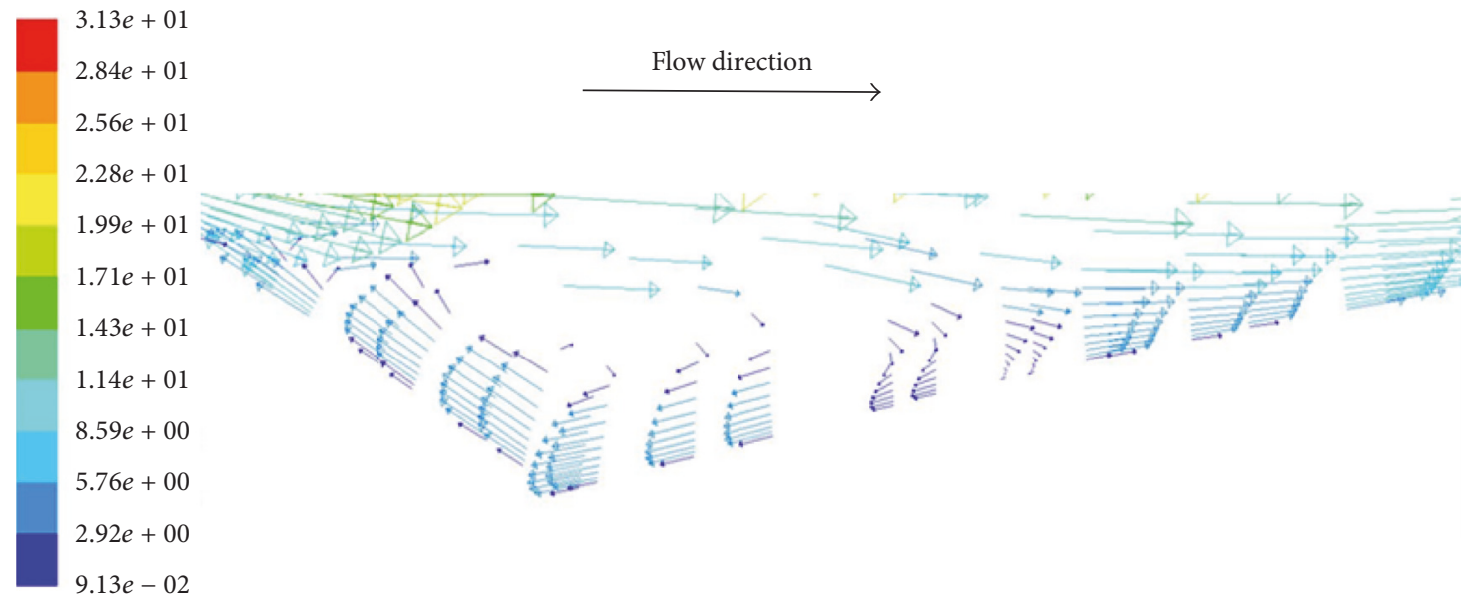

FIGURE 8: Enlargement of region 1.

TABLE 4: Orthogonal test table.

\begin{tabular}{lccc}
\hline Test number & Test factors & Spacing $(\mathrm{mm})$ \\
\hline 1 & Depth $(\mathrm{mm})$ & Angle of repose $\left(^{\circ}\right)$ & $(1) 25$ \\
2 & $(1) 4$ & $(1) 31$ & $(2) 30$ \\
3 & $(1) 4$ & $(2) 33$ & $(3) 35$ \\
4 & $(1) 4$ & $(3) 35$ & $(2) 30$ \\
5 & $(2) 7$ & $(1) 31$ & $(3) 35$ \\
6 & $(2) 7$ & $(2) 33$ & $(1) 25$ \\
7 & $(2) 7$ & $(3) 35$ & $(3) 35$ \\
8 & $(3) 9$ & $(1) 31$ & $(1) 25$ \\
9 & $(3) 9$ & $(2) 33$ & $(2) 30$ \\
Smooth surface & $(3) 9$ & $(3) 35$ & 0 \\
\hline
\end{tabular}


TABLE 5: Intuitive analysis of numerical simulation tests results.

\begin{tabular}{|c|c|c|c|c|}
\hline Test number & $\begin{array}{c}A \\
\text { Depth } h(\mathrm{~mm}) \\
\end{array}$ & $\begin{array}{c}B \\
\text { Angle of repose } \alpha\left(^{\circ}\right)\end{array}$ & $\begin{array}{c}C \\
\text { Spacing } d(\mathrm{~mm})\end{array}$ & Result $R_{D}$ \\
\hline 1 & 1 & 1 & 1 & $28.54 \%$ \\
\hline 2 & 1 & 2 & 2 & $27.98 \%$ \\
\hline 3 & 1 & 3 & 3 & $27.82 \%$ \\
\hline 4 & 2 & 1 & 2 & $29.96 \%$ \\
\hline 5 & 2 & 2 & 3 & $28.85 \%$ \\
\hline 6 & 2 & 3 & 1 & $33.63 \%$ \\
\hline 7 & 3 & 1 & 3 & $28.63 \%$ \\
\hline 8 & 3 & 2 & 1 & $32.69 \%$ \\
\hline 9 & 3 & 3 & 2 & $31.15 \%$ \\
\hline$K_{1}$ & 0.84 & 0.87 & 0.95 & \\
\hline$K_{2}$ & 0.92 & 0.90 & 0.89 & \\
\hline$K_{3}$ & 0.92 & 0.93 & 0.85 & \\
\hline$k_{1}$ & 0.28 & 0.29 & 0.32 & \\
\hline$k_{2}$ & 0.31 & 0.30 & 0.30 & \\
\hline$k_{3}$ & 0.30 & 0.31 & 0.28 & \\
\hline$R$ & 0.03 & 0.02 & 0.04 & \\
\hline Optimal level & $A_{2}$ & $B_{3}$ & $C_{1}$ & \\
\hline Major factor & $C$ & A & $B$ & \\
\hline
\end{tabular}

TABLE 6: Variance analysis of numerical simulation test results.

\begin{tabular}{lccccc}
\hline Source & Sum of squares & DOF & Mean sum of square & $F$ value & Significance level $\alpha$ \\
\hline Depth & 0.00146342 & 2 & 0.00073171 & 19.75 & 6.77 \\
Angle of repose & 0.00050133 & 2 & 0.00025066 & 20.85 & 0.05 \\
Spacing & 0.00154501 & 2 & 0.00077250 & - & 0.05 \\
Error & 0.00007409 & 2 & 0.00003704 & $F 0.1(2,2)=9$ \\
\hline Grand total & 0.00358384 & 8 & $F 0.05(2,2)=19$ & \\
\hline
\end{tabular}

As shown in Figure 8, a low-speed swirl is formed within the nonsmooth unit, and the shapes of every swirl are approximately the same. The rotation direction at the bottom of the swirl is opposite the fluid direction, and the rotation direction at the top of the swirl is the same as the fluid direction. Because of the presence of the swirl, when the fluid flows along the wall to the nonsmooth area, fluid will flow from the top of the nonsmooth units instead of along the inner wall of the nonsmooth units. The gas-gas contact between the swirl and external fluid replaces the original gassolid contact between the fluid and object surfaces. The swirl is similar to the roller bearing that converts sliding friction (caused by the object surfaces and fluid) into rolling friction, leading to skin friction reduction.

3.2.2. Variation of the Turbulent Boundary Layer Thickness. Flow field velocity contours for the middle cross-section along the incoming flow direction were extracted (Figure 9). Region 2 and region 3 are enlarged in Figure 10. It is obvious that the turbulent boundary layer thickness of the nonsmooth surface is greater than that of the smooth surface. To accurately compare the turbulent boundary layer thickness of the smooth and nonsmooth surfaces, the fluid speed and height were extracted at a middle position $430 \mathrm{~mm}$ from the entrance (Figure 11). With the speed change from $10 \mathrm{~m} / \mathrm{s}$ to $30 \mathrm{~m} / \mathrm{s}$, the turbulent boundary layer thickness continues to decrease for both smooth and nonsmooth surfaces, and the turbulent boundary layer thickness of the nonsmooth surface is greater than that of the smooth surface at all times.

It is obvious that the nonsmooth structure can increase the thickness of the turbulent boundary layer. The thicker the turbulent boundary layer, the smaller the velocity gradient. The velocity gradient is correlated with the fluid shear stress, which is the interaction force between the fluid and object surface. Therefore, the magnitude of the shear stress characterizes the magnitude of skin friction.

Shear stress contours of smooth and nonsmooth surfaces were also extracted (Figure 12). According to the contours, it is obvious that the nonsmooth surface experiences smaller shear stresses than the smooth surface. Therefore, wall shear 

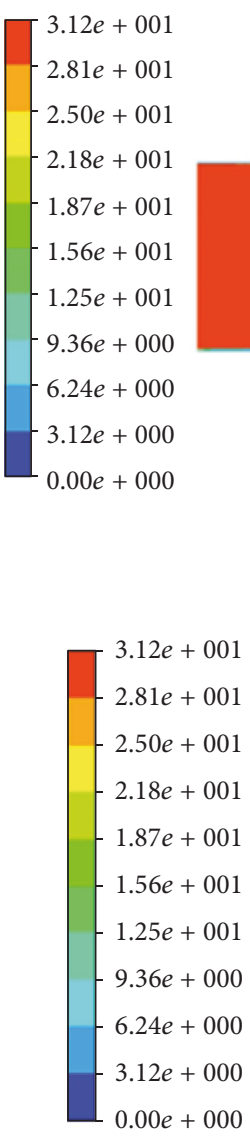

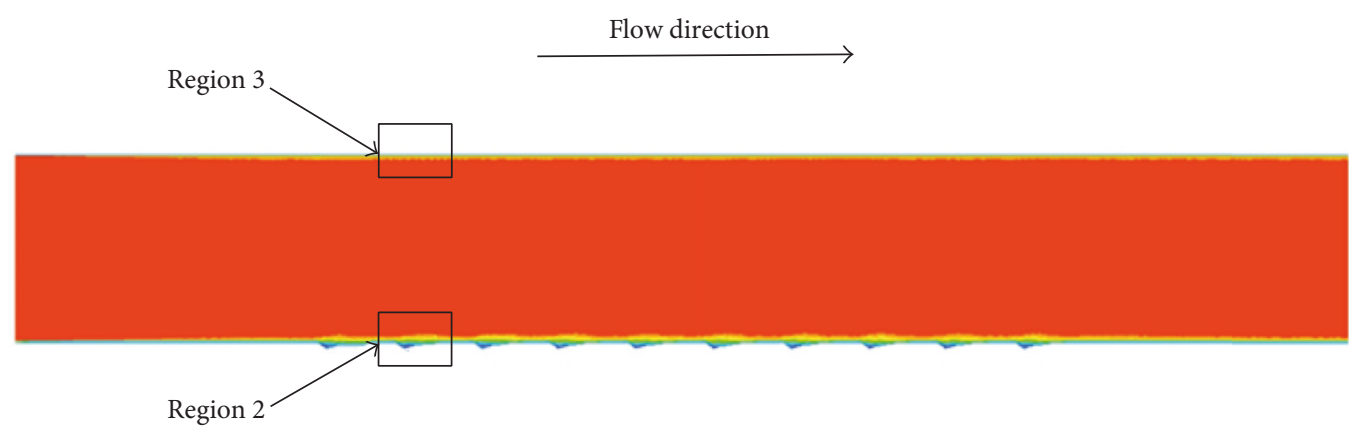

FIGURE 9: Velocity contour of the middle cross-section.
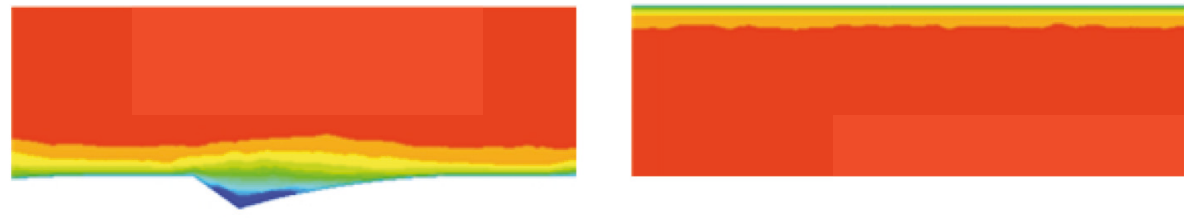

FIGURE 10: Enlargements of regions 2 and 3.

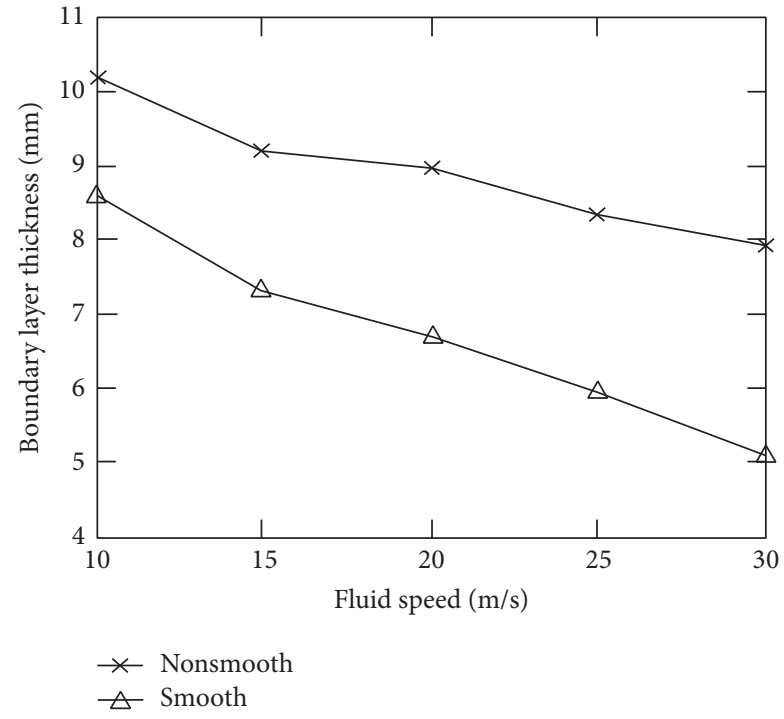

FIGURE 11: Variation in turbulent boundary layer thickness with fluid speed.

stress is reduced by decreasing the turbulent boundary layer thickness of the nonsmooth structure in order to reduce skin friction.

\section{PIV Tests in the Wind Tunnel}

To further validate the accuracy of the flow field around the nonsmooth units, PIV technology was used in a wind tunnel to measure the flow fields around nonsmooth units. PIV measurement technology has the characteristics of noncontact and high accuracy and is very suitable for measuring flow fields within a nonsmooth structure. A low-speed reflux wind tunnel was adopted in the PIV test. The designed wind speeds range from 0.5 to $40 \mathrm{~m} / \mathrm{s}$, and the size of test section is $0.3 \times$ $0.3 \mathrm{~m}$. The PIV system includes a light source system (tworesonator laser), an image acquisition system (high resolution CCD camera), a control coordination system (synchronizer), special PIV image data processing technology, and a flow field display system (insight package and external interface). The tracer particles used in the test are atomized oil produced by a particle generator. To allow the experimental results to be compared with the simulation results, the size of the experimental model produced with $3 \mathrm{D}$ printing technology is identical to the simulation model. The placement of the model in the wind tunnel is shown in Figure 13.

The original image was obtained from the TSI INSIGHT $4 \mathrm{G}$ software by collecting a large number of image data. The flow field around the nonsmooth unit was obtained from data processing. Figure 14 shows an original image of the velocity vector field distribution perpendicular to the cross-section 


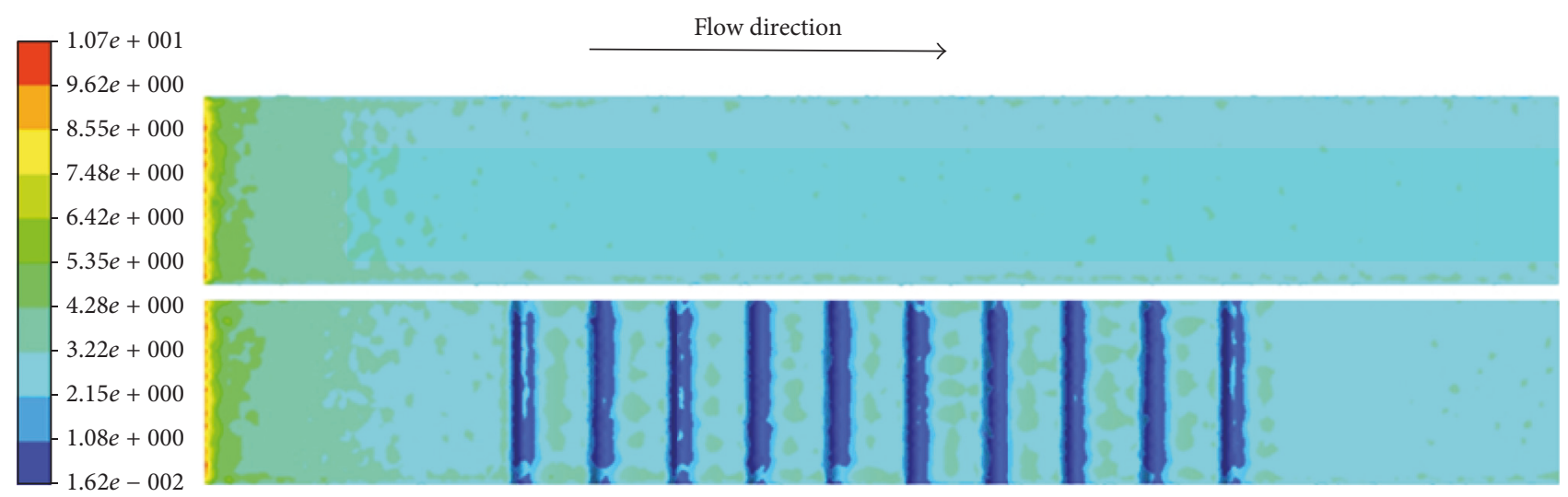

FIGURE 12: Shear stress contours of nonsmooth and smooth surfaces.

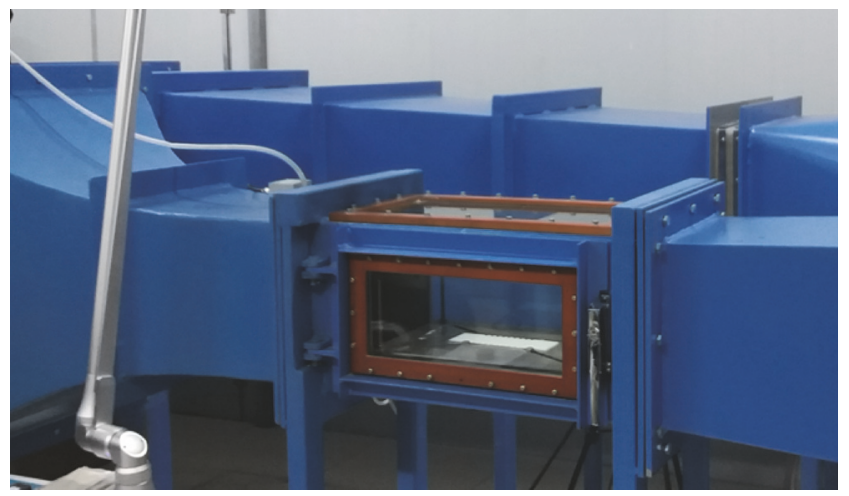

FIGURE 13: Placement of the model in the wind tunnel.

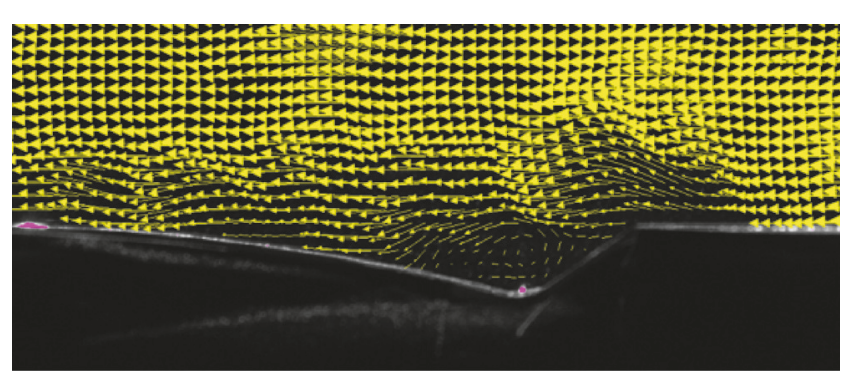

FIGURE 14: Velocity vector field distribution.

of the $y$-axis; additionally, the image captures the air flow around the nonsmooth surface well. The nonsmooth unit was enlarged in Figure 15. According to Figure 15, it is obvious that there is a low-speed swirl within the nonsmooth unit.

Comparing Figure 15 with Figure 8 (obtained by numerical simulation), it can be found that the flow trends obtained from PIV test results are consistent to those observed in simulation results. The flow directions are the same, and there is a very obvious swirl in both the PIV tests and numerical simulations. The PIV test results are in close agreement with the simulation results.

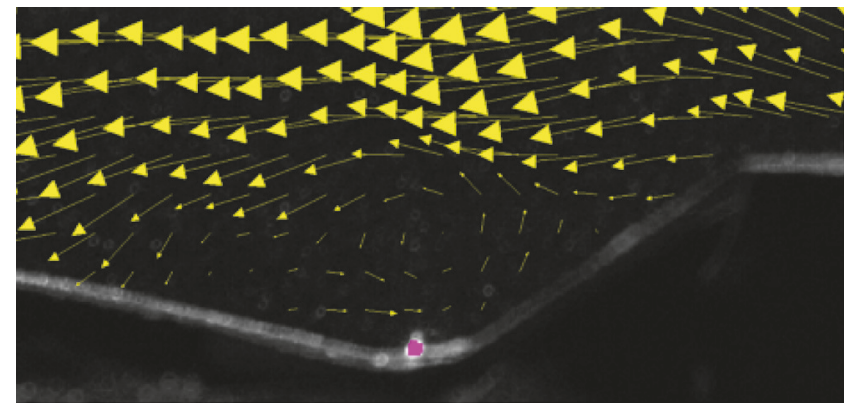

FIGURE 15: Enlargement of the nonsmooth unit.

\section{Conclusions}

In this study, a new bionic nonsmooth surface inspired by the shape of barchan dunes has been proposed. The novel nonsmooth surface surpasses the limitations of existing bionic nonsmooth structures. Numerical simulation tests found that the surface has a significant skin friction reduction effect, with a maximum drag reduction of $33.63 \%$ at a fluid speed of $30 \mathrm{~m} / \mathrm{s}$. The main conclusions are as follows:

(1) The primary and secondary factors influencing the skin friction reduction rate of the nonsmooth surface are spacing $(d)$, depth $(h)$, and angle of repose $(\alpha)$. The depth $(h)$ and spacing $(d)$ have significant effects on skin friction reduction.

(2) The mechanisms of nonsmooth surfaces for reducing skin friction have been discussed with respect to three different characteristics. First, the coherent structure generated within the nonsmooth unit causes regular disturbances to the turbulent flow and this maintains the stability of the flow. Second, a low-speed roller-bearing-like swirl is formed within the nonsmooth unit, which translates sliding friction between the object surface and fluid into rolling friction, leading to skin friction reductions. Finally, the nonsmooth unit blocks fluid movement, and a thick low-speed fluid is formed within the nonsmooth unit. The low-speed fluid increases the boundary layer thickness and reduces the wall shear stress leading to skin friction reduction. 
Changes in the flow field within the nonsmooth unit were captured in the PIV test conducted in a low-speed reflux wind tunnel. The PIV test confirms the existence of the lowspeed swirl within the nonsmooth unit and achieves good agreement with the simulation results.

The study was limited to low-speed air flow ranging from 10 to $30 \mathrm{~m} / \mathrm{s}$. Further investigation is warranted into highspeed or super-high-speed air flows, for aeronautical applications. The flow field characteristics of the new nonsmooth surface in water flow would also be worthy of investigation, for potential future applications in underwater vehicles or ships. The application directions of the new nonsmooth surfaces discussed in this study include, but are not limited to, aerodynamic drag reduction in the automotive field. Because of the good skin friction reduction performance of the plate, the new nonsmooth surface can be applied to automobiles as a film coating in future studies. Automotive wind tunnel tests or real vehicle road tests could also be conducted to further explore the aerodynamic drag reduction effect.

\section{Conflicts of Interest}

The authors declare that there are no conflicts of interest regarding the publication of this paper.

\section{Acknowledgments}

The work reported in this paper was supported by the National Natural Science Foundation of China (no. 51375439).

\section{References}

[1] W. Li, W. Jessen, D. Roggenkamp et al., "Turbulent drag reduction by spanwise traveling ribbed surface waves," European Journal of Mechanics B/Fluid, vol. 53, pp. 101-102, 2015.

[2] S. L. Ceccio, "Friction drag reduction of external flows with bubble and gas injection," Annual Review of Fluid Mechanics, vol. 42, pp. 183-203, 2010.

[3] G. H. Wang and N. Jiang, "Influence of periodic disturbance on statistic character of turbulent boundary layer," Journal of Aerospace Power, vol. 22, no. 9, pp. 1505-1511, 2007.

[4] Y. Yao, JL. Luo, H. Liu et al., "Water tunnel experimental investigation on drag reduction of coating surface wall," Procedia Engineering, vol. 126, pp. 247-253, 2015.

[5] N. J. Shirtcliffe, G. Mchale, M. I. Newton et al., "Superhydrophobic copper tubes with possible flow enhancement and drag reduction," ACS Applied Materials \& Interfaces, vol. 1, no. 6, pp. 1316-1323, 2009.

[6] A. D. Lucey and P. W. Carpenter, "A numerical simulation of the interaction of a compliant wall and inviscid flow," Journal of Fluid Mechanics, vol. 234, pp. 121-146, 1992.

[7] J. Oeffner and G. V. Lauder, "The hydrodynamic function of shark skin and two biomimetic applications," Journal of Experimental Biology, vol. 215, no. 5, pp. 785-795, 2012.

[8] B. R. Elbing, E. S. Winkel, K. A. Lay, S. L. Ceccio, D. R. Dowling, and M. Perlin, "Bubble-induced skin-friction drag reduction and the abrupt transition to air-layer drag reduction," Journal of Fluid Mechanics, vol. 612, pp. 201-236, 2008.
[9] W. C. Sanders, E. S. Winkel, D. R. Dowling, M. Perlin, and S. L. Ceccio, "Bubble friction drag reduction in a high-Reynoldsnumber flat-plate turbulent boundary layer," Journal of Fluid Mechanics, vol. 552, pp. 353-380, 2006.

[10] H. Mamori and K. Fukagata, "Drag reduction effect by a wavelike wall-normal body force in a turbulent channel flow," Physics of Fluids, vol. 26, no. 11, Article ID 115104, 2014.

[11] R. D. Bullen and N. L. McKenzie, "The pelage of bats (Chiroptera) and the presence of aerodynamic riblets: the effect on aerodynamic cleanliness," Zoology, vol. 111, no. 4, pp. 279-286, 2008.

[12] B. Dean and B. Bhushan, "Shark-skin surfaces for fluid-drag reduction in turbulent flow: a review," Philosophical Transactions of the Royal Society A: Mathematical, Physical and Engineering Sciences, vol. 368, no. 1929, pp. 4775-4806, 2010.

[13] B. Dean and B. Bhushan, "The effect of riblets in rectangular duct flow," Applied Surface Science, vol. 258, no. 8, pp. 39363947, 2012.

[14] Z. Dou, J. Wang, and D. Chen, "Bionic research on fish scales for drag reduction," Journal of Bionic Engineering, vol. 9, no. 4, pp. 457-464, 2012.

[15] G. D. Bixler and B. Bhushan, "Shark skin inspired low-drag microstructured surfaces in closed channel flow," Journal of Colloid \& Interface Science, vol. 393, no. 1, pp. 384-396, 2012.

[16] O. A. EI-Samni, H. H. Chun, and H. S. Yoon, "Drag reduction of turbulent flow over thin rectangular riblets," International Journal of Engineering Science, vol. 45, no. 2-8, pp. 436-454, 2007.

[17] O. A. EI-Samni, H. S. Yoon, and H. H. Chun, "Turbulent flow over thin rectangular riblets," Journal of Mechanical Science \& Technology, vol. 19, no. 9, pp. 1801-1810, 2005.

[18] J. Szodruch, "Viscous drag reduction on transport aircraft," in Proceedings of the Aerospace Sciences Meeting, Reno, NV, USA, 1991.

[19] Q. G. Huang, G. Pan, Hu. HB et al., "Investigation about drag reduction characteristic of riblets surface on vehicle model in water tunnel," Journal of Experiments in Fluid Mechanics, vol. 24, no. 3, pp. 50-53, 2010.

[20] Y. H. Luo and D. Y. Zhang, "Investigation on fabricating continuous vivid sharkskin surface by bio-replicated rolling method," Applied Surface Science, vol. 282, pp. 370-375, 2013.

[21] S.-J. Lee and S.-H. Lee, "Flow field analysis of a turbulent boundary layer over a riblet surface," Experiments in Fluids, vol. 30, no. 2, pp. 153-166, 2001.

[22] P. Luchini, F. Manzo, and A. Pozzi, "Resistance of a grooved surface to parallel flow and cross-flow," Journal of Fluid Mechanics, vol. 228, pp. 87-109, 1991.

[23] S. Yao, D. Guo, Z. Sun, and G. Yang, "A modified multi-objective sorting particle swarm optimization and its application to the design of the nose shape of a high-speed train," Engineering Applications of Computational Fluid Mechanics, vol. 9, no. 1, pp. 513-527, 2015.

[24] J. Kim, M. Yadav, and S. Kim, "Characteristics of secondary flow induced by 90 -degree elbow in turbulent pipe flow," Engineering Applications of Computational Fluid Mechanics, vol. 8, no. 2, pp. 229-239, 2014.

[25] L. Dong and L. X. Cao, "Effects of residual riblets of impeller's hub surface on aerodynamic performance of centrifugal compressors," Engineering Applications of Computational Fluid Mechanics, vol. 9, no. 1, pp. 99-113, 2015. 
[26] Z. Sun, Y. Zhang, D. Guo, G. Yang, and Y. Liu, "Research on running stability of CRH3 high speed trains passing by each other," Engineering Applications of Computational Fluid Mechanics, vol. 8, no. 1, pp. 140-157, 2014.

[27] G. Sauermann, P. Rognon, A. Poliakov, and H. J. Herrmann, "The shape of the barchan dunes of Southern Morocco," Geomorphology, vol. 36, no. 1-2, pp. 47-62, 2000.

[28] A. Faheem, G. Ranzi, F. Fiorito, and C. Lei, "A numerical study of turbulent mixed convection in a smooth horizontal pipe," Journal of Heat Transfer, vol. 138, no. 1, Article ID 012501, 11 pages, 2016.

[29] M. Li, T. S. Khan, E. Al-Hajri, and Z. H. Ayub, "Single phase heat transfer and pressure drop analysis of a dimpled enhanced tube," Applied Thermal Engineering, vol. 101, pp. 38-46, 2016.

[30] T. H. Shih, W. W. Liou, A. Shabbir et al., "A new $k-\epsilon$ eddy viscosity model for high reynolds number turbulent flows," Computers \& Fluids, vol. 24, no. 3, pp. 227-238, 1995.

[31] B. E. Launder and D. B. Spalding, "The numerical computation of turbulent flows," Computer Methods in Applied Mechanics and Engineering, vol. 3, no. 2, pp. 269-289, 1974.

[32] Z. J. Yang, X. D. Yang, and Q. C. Wang, "Orthogonal design investigation on wear resistance with non-smooth surface," Applied Mechanics \& Materials, vol. 274, pp. 455-458, 2013.

[33] H. Zhou, G. Wang, Y. Ding, J. Yang, and H. Zhai, "Investigation of the effect of dimple bionic nonsmooth surface on tire antihydroplaning," Applied Bionics and Biomechanics, vol. 2015, Article ID 694068, 10 pages, 2015.

[34] S. K. Robinson, "Coherent motions in the turbulent boundary layer," Annual Review of Fluid Mechanics, vol. 23, no. 1, pp. 601639, 1991. 


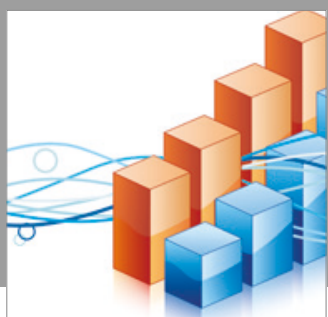

Advances in

Operations Research

vatersals

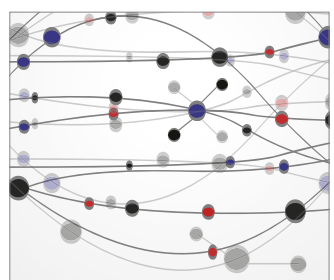

\section{The Scientific} World Journal
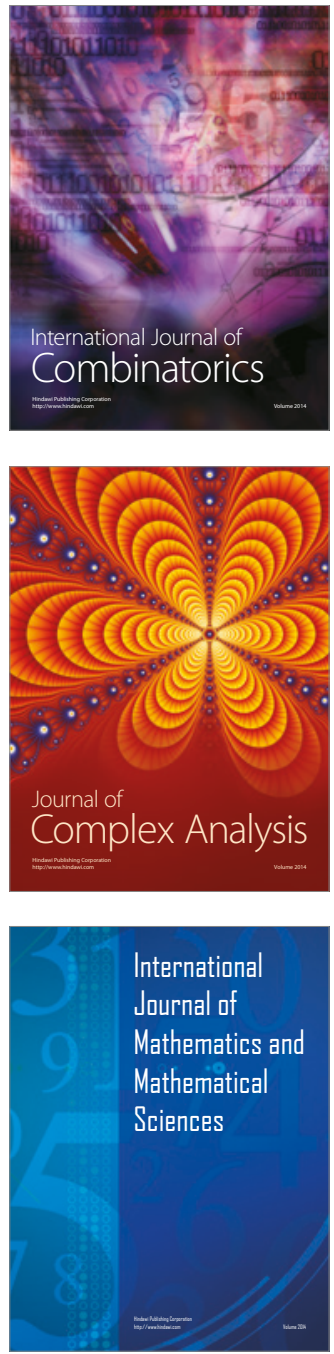
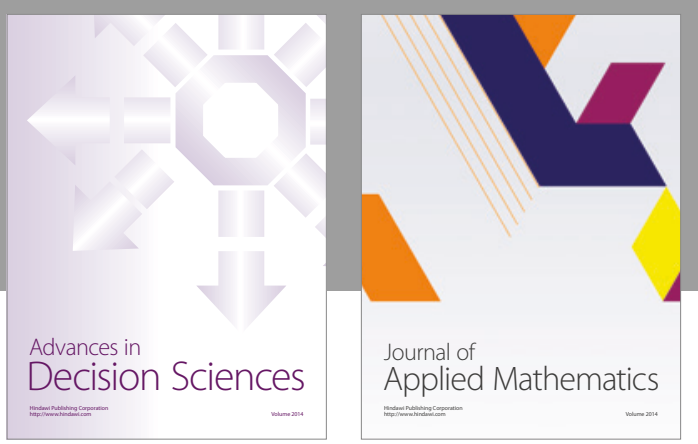

Algebra

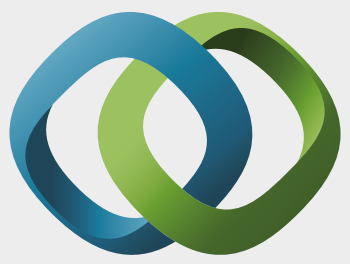

\section{Hindawi}

Submit your manuscripts at

https://www.hindawi.com
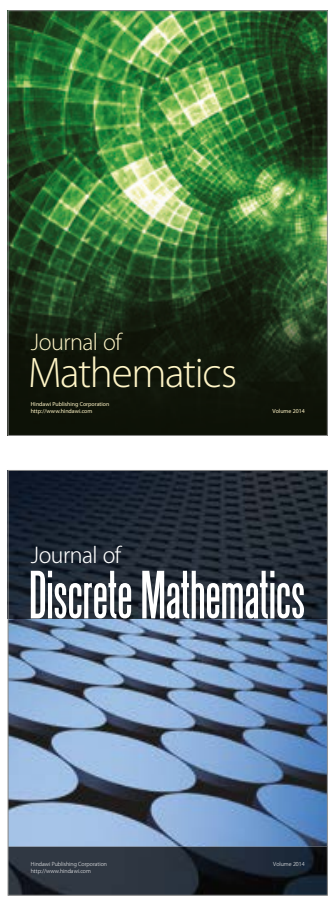

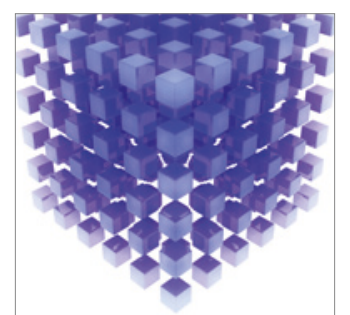

Mathematical Problems in Engineering
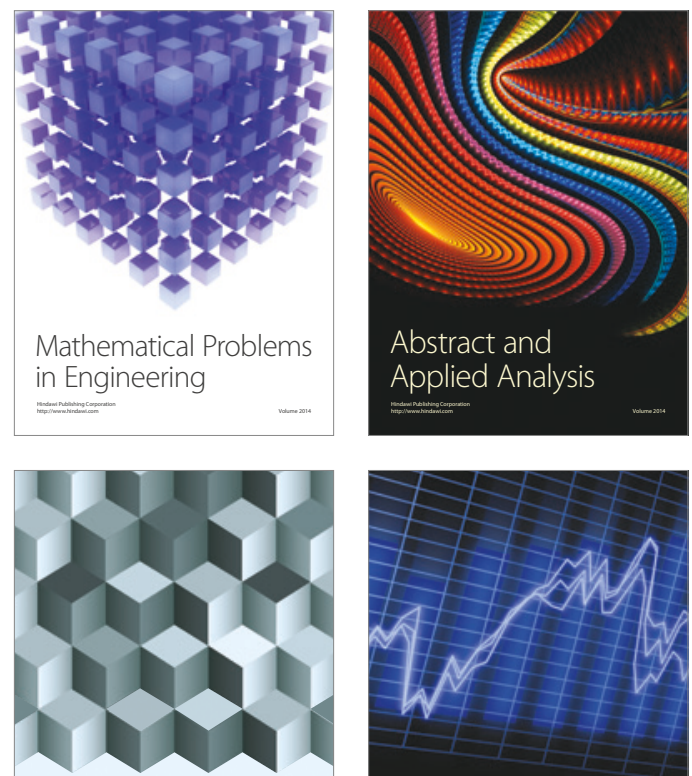

Journal of

Function Spaces

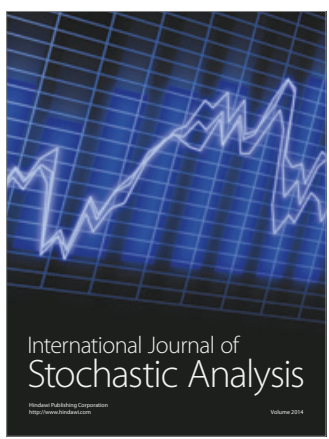

Probability and Statistics
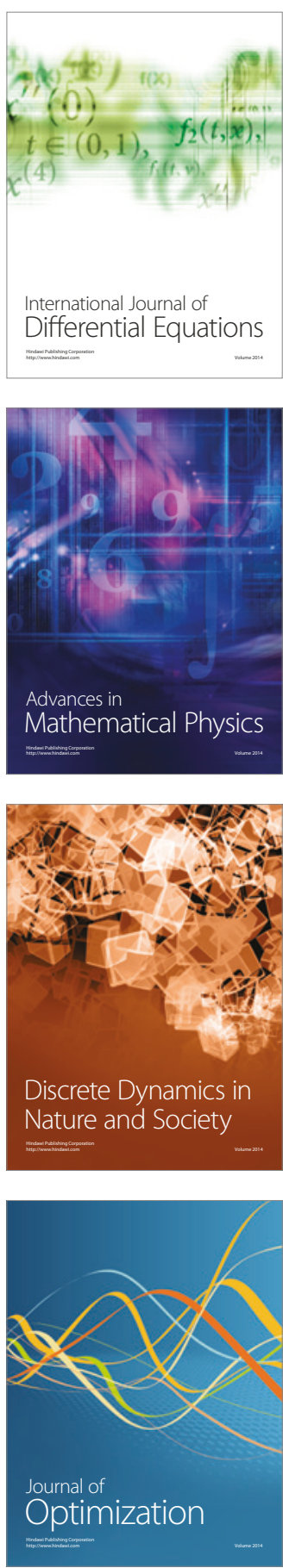